\title{
Etoposide-mediated interleukin-8 secretion from bone marrow stromal cells induces hematopoietic stem cell mobilization
}

Ka-Won Kang', Seung-Jin Lee ${ }^{2,3}$, Ji Hye Kim²,3, Byung-Hyun Lee' ${ }^{1}$, Seok Jin Kim', Yong Park ${ }^{1}$ and Byung SoO Kim ${ }^{1,2,3^{*}}$ (D)

\begin{abstract}
Background: We assessed the mechanism of hematopoietic stem cell (HSC) mobilization using etoposide with granulocyte-colony stimulating factor (G-CSF), and determined how this mechanism differs from that induced by cyclophosphamide with G-CSF or G-CSF alone.

Methods: We compared the clinical features of 173 non-Hodgkin's lymphoma patients who underwent autologous peripheral blood stem cell transplantation (auto-PBSCT). Additionally, we performed in vitro experiments to assess the changes in human bone marrow stromal cells (hBMSCs), which support the HSCs in the bone marrow (BM) niche, following cyclophosphamide or etoposide exposure. We also performed animal studies under standardized conditions to ensure the following: exclude confounding factors, mimic the conditions in clinical practice, and identify the changes in the BM niche caused by etoposide-induced chemo-mobilization or other mobilization methods.

Results: Retrospective analysis of the clinical data revealed that the etoposide with G-CSF mobilization group showed the highest yield of CD34+ cells and the lowest change in white blood cell counts during mobilization. In in vitro experiments, etoposide triggered interleukin (IL)-8 secretion from the BMSCS and caused long-term BMSC toxicity. To investigate the manner in which the hBMSC-released IL-8 affects hHSCs in the BM niche, we cultured hHSCs with or without IL-8, and found that the number of total, CD34+, and CD34+/CD45- cells in IL-8-treated cells was significantly higher than the respective number in hHSCs cultured without IL-8 ( $p=0.014,0.020$, and 0.039 , respectively).

Additionally, the relative expression of CXCR2 (an IL-8 receptor), and mTOR and C-MYC (components of IL-8-related signaling pathways) increased $1 \mathrm{~h}$ after IL-8 treatment. In animal studies, the etoposide with G-CSF mobilization group presented higher IL-8-related cytokine and MMP9 expression and lower SDF-1 expression in the BM, compared to the groups not treated with etoposide.
\end{abstract}

(Continued on next page)

\footnotetext{
* Correspondence: kbs0309@korea.ac.kr

'Division of Hematology-Oncology, Department of Internal Medicine, Korea University School of Medicine, 73, Goryeodae-ro, Seongbuk-gu, Seoul 02841, South Korea

${ }^{2}$ Institute of Stem Cell Research, Korea University, Seoul, South Korea

Full list of author information is available at the end of the article
}

(c) The Author(s). 2020 Open Access This article is licensed under a Creative Commons Attribution 4.0 International License, which permits use, sharing, adaptation, distribution and reproduction in any medium or format, as long as you give appropriate credit to the original author(s) and the source, provide a link to the Creative Commons licence, and indicate if changes were made. The images or other third party material in this article are included in the article's Creative Commons licence, unless indicated otherwise in a credit line to the material. If material is not included in the article's Creative Commons licence and your intended use is not permitted by statutory regulation or exceeds the permitted use, you will need to obtain permission directly from the copyright holder. To view a copy of this licence, visit http://creativecommons.org/licenses/by/4.0/ The Creative Commons Public Domain Dedication waiver (http://creativecommons.org/publicdomain/zero/1.0/) applies to the data made available in this article, unless otherwise stated in a credit line to the data. 


\begin{abstract}
(Continued from previous page)
Conclusion: Collectively, the unique mechanism of etoposide with G-CSF-induced mobilization is associated with IL-8 secretion from the BMSCs, which is responsible for the enhanced proliferation and mobilization of HSCs in the bone marrow; this was not observed with mobilization using cyclophosphamide with G-CSF or G-CSF alone. However, the long-term toxicity of etoposide toward BMSCs emphasizes the need for the development of more efficient and safe chemo-mobilization strategies.
\end{abstract}

Keywords: Hematopoietic stem cell mobilization, Etoposide, Cyclophosphamide, G-CSF

\section{Background}

Successful autologous peripheral blood stem cell transplantation (auto-PBSCT) for hematological malignancies requires harvesting a sufficient number of human hematopoietic stem cells (hHSCs) mobilized from the bone marrow $(\mathrm{BM})$ to the peripheral blood $(\mathrm{PB})$. In clinical practice, the mobilization protocols generally include chemotherapy and granulocyte colony-stimulating factor (G-CSF) (chemo-mobilization), as restricting the cancer burden during mobilization is crucial. Since the first clinical application of G-CSF by Dührsen et al. in 1988 [1], cyclophosphamide chemo-mobilization has been commonly used for chemo-mobilization [2, 3]. Cyclophosphamide induces the release of stress signals that cause inflammation, thereby activating the host immune system, which may increase hHSC mobilization $[4,5]$. However, this protocol has some disadvantages, including-primarily-the unpredictability of the number of hHSCs that can be collected from the PB and the possibility of mobilization-related toxicities, such as febrile neutropenia [5-7]. Reiser et al. had first reported the use of etoposide as an alternative to cyclophosphamide to effectively mobilize PBSCs in patients in whom cyclophosphamide-induced chemo-mobilization had failed [8]; this led to studies on etoposide-induced chemo-mobilization (Supplementary Material 1: Table S1) [9-13]. However, concerns regarding the use of etoposide include its inhibition of topoisomerase 2, which damages DNA. Cancer patients undergoing chemotherapy regimens that include etoposide, have been reported to experience secondary hematological malignancies [14, 15]. Moreover, Gibson et al. demonstrated that etoposide could damage human bone marrow stromal cells (hBMSCs) [16]. These findings suggest that etoposide may influence the BM niche by not only enhancing hHSC mobilization but also by inducing BM damage. Therefore, the mechanism underlying etoposide-induced mobilization may differ from that of G-CSF- or cyclophosphamide-induced mobilization, which proceeds through the demargination of HSCs from the BM to PB due to systemic inflammation [17]. However, to date, this topic appears to have received little attention. Furthermore, verification of the mobilization mechanisms may be difficult due to the interference of complex physical conditions in patients, which could confound the interpretation of the associated clinical findings. To overcome these barriers, we designed a three-step study involving the following: 1) analysis of clinical data associated with auto-PBSCT in patients with non-Hodgkin's lymphoma (NHL); 2) in vitro experiments to assess the changes in hBMSCs, which support HSCs in the BM niche, after exposure to cyclophosphamide or etoposide; and 3) in vivo animal studies under standardized conditions to exclude confounding factors, mimic conditions of clinical practice, and identify changes in the BM niche caused by etoposide-induced chemo-mobilization or other mobilization protocols.

\section{Methods}

Clinical data

The clinical data of patients with Non-Hodgkin Lymphoma (NHL) who underwent PB stem cell collection (PBSCC) at the Korea University Anam Hospital and the Samsung Medical Center, from 2005 to 2019, was retrospectively analyzed, and a retrospective chart review was conducted. Both these studies were approved by an internal board of the Korea University Anam Hospital (IRB No. 2019AN0386) and the Samsung Medical Center (2019-09-085-001).

\section{Primary hBMSC culture}

The internal review board of the Korea University Anam Hospital (IRB No. 2015AN0267) approved all the procedures. Written informed consent was obtained from all subjects. The subjects were healthy individuals who donated $\mathrm{BM}$ via $\mathrm{BM}$ harvesting. A total of $20 \mathrm{~mL} B M$ was collected from each subject. Mononuclear cells (MNCs) were separated using Ficoll-Paque ${ }^{\mathrm{Tw}}$ Plus medium (GE Healthcare Life Sciences, Seoul, South Korea); the remaining cells were cultured in mesenchymal stem cell growth medium (Lonza, Walkersville, MD, USA). In this study, we used isolated hBMSCs within five passages from the start of the subculture and routinely tested to confirm the absence of mycoplasma by the e$\mathrm{Myco}^{\mathrm{m}}$ VALiD mycoplasma PCR detection kit (iNtRON, Burlington, MA, USA). 


\section{Flow cytometry}

Antibodies against anti-human CD73-PE, CD90-PE, CD105-PE, CD34-FITC, and CD45-PE (Becton Dickinson, San Jose, CA, USA) were used at 1:100 dilution. Cells were analyzed using FACSCalibur ${ }^{\text {Tit }}$ (Becton Dickinson).

\section{Chemotherapeutic agents and cytotoxicity assay}

Commercially available preparations of cyclophosphamide (Endoxan injection, $500 \mathrm{mg}$; Boxter Inc., Seoul, South Korea) and etoposide (Lastet injection, $100 \mathrm{mg} / 5$ $\mathrm{mL}$; Dong-A Inc., Seoul, South Korea) were used. Cell Counting Kit-8 (CCK-8 assay, Dojindo Laboratories, Japan) was used for the cytotoxicity assays, according to the manufacturer's instructions. Absorbance was measured at $450 \mathrm{~nm}$ using a SpectraMax Plus 384 spectrophotometer (Molecular Devices Corporation, CA, USA).

\section{Human and mouse cytokine arrays}

The Human Cytokine Antibody Array C1000 and Mouse Cytokine Antibody Array C1000 (both from Ray Biotech, GA, USA) were used, according to the manufacturer's instructions. Images were acquired using a ChemiDoc ${ }^{\mathrm{Tx}}$ Touch Imaging System (Bio-Rad, Hercules, CA, USA) and quantified using ImageJ (National Institutes of Health, MD, USA). Signal was normalized using the internal positive controls and the background with the RayBio ${ }^{\circ}$ Antibody Array Analysis Tool (Ray Biotech).

\section{Apoptosis and cell cycle analysis}

Apoptosis analysis was performed using the EzWay Annexin V-FITC Apoptosis Detection Kit (Koma Biotech Inc., Seoul, South Korea). Cell-cycle distribution analysis was performed using propidium iodide at $50 \mathrm{mg} / \mathrm{mL}$ (Sigma-Aldrich, catalog no. P4170). Both assays were performed according to the manufacturers' instructions.

\section{HSC culture and IL-8 treatment}

Human BM CD34+ HSCs were purchased from Lonza (catalog no. $2 \mathrm{M}-101$ ) and cultured in Stemline ${ }^{\circ}$ II Hematopoietic Stem Cell Expansion Medium (SigmaAldrich, catalog no. S0192) containing $100 \mathrm{ng} / \mathrm{mL}$ stem cell factor, thrombopoietin, and G-CSF (all obtained from R\&D Systems, Inc., Minneapolis, MN, USA). Recombinant human IL-8/CXCL8 protein was acquired from R\&D Systems (catalog no. 208-IL).

\section{Quantitative reverse transcription-polymerase chain reaction (qRT-PCR)}

Total RNA was isolated from cells using the Qiagen RNeasy kit (Qiagen, Hilden, Germany) and quantified using a NanoDrop spectrophotometer (Thermo Fisher Scientific, Inc., Waltham, MA, USA). cDNA was synthesized using $2 \mu \mathrm{g}$ total RNA as a template in a $20-\mu \mathrm{L}$ reaction mixture containing oligos, primers, and Superscript II reverse transcriptase (Thermo Fisher Scientific, Inc.), according to the manufacturer's instructions. Synthesized cDNA was amplified using the iQ SYBR Green qPCR Master Mix (Bio-Rad) on a Bio-Rad iCycler iQ (Bio-Rad). Comparative threshold cycle values were normalized to those of glyceraldehyde-3-phosphate dehydrogenase. The primers used are described in Supplementary Material 2: Table S2. To compare the difference in mRNA expression, relative quantification was performed using the delta-delta Ct method [18]. In brief, the $\Delta \mathrm{Ct}$ value was obtained after normalization based on the internal control (GAPDH), and the $\Delta \Delta \mathrm{Ct}$ value was obtained based on the control group. We then used $2^{-\Delta \Delta C t}$ to calculate the fold change.

\section{Mice}

All experimental procedures using animals complied with the guidelines of the Laboratory Animal Research Center of the Korea University College of Medicine (IRB No. KOREA-2017-0176). A total of 87 C57BL/6 N mice were purchased from Orient Bio (Seongnam, South Korea). Mice, 8 weeks of age and with a body weight of $20 \mathrm{~g}$, were maintained in polypropylene cages under specific pathogen-free conditions, with light/dark 12-h cycles, at $21 \pm 2{ }^{\circ} \mathrm{C}$, and had ad libitum access to a maintenance diet. Sample sizes were calculated using a pilot study and the G*Power program (http://www.gpower.hhu.de/). All analyses were conducted blindly to minimize the effects of subjective bias.

\section{Protocol for HSC mobilization in mice}

The mouse model of HSC mobilization was designed based on protocol used in human patients (Fig. 4a-b). A previously reported model of cyclophosphamide chemomobilization was used in this study [19]. Due to the apparent lack of a related animal model, we developed a new model of etoposide chemo-mobilization. Mice were injected intraperitoneally with $4 \mathrm{mg}$ cyclophosphamide $(\approx 200 \mathrm{mg} / \mathrm{kg})$ on day 1 (D1) or with $0.8 \mathrm{mg}$ etoposide $(\approx$ $40 \mathrm{mg} / \mathrm{kg}$ ) on days 1 and 2 (D1, D2). Subsequently, $5 \mu \mathrm{g}$ human G-CSF $(250 \mu \mathrm{g} / \mathrm{kg}$ per day; Leucostim prefilled syringe INJ, Dong-A Inc.) was administered daily as a single subcutaneous injection, on each successive day from day 3 , for a total of 4 days. All mice were euthanized on D7 by cardiac puncture and cervical dislocation under anesthesia. On day 7 (D7), we isolated hematopoietic progenitor cells (HPCs) using an Easy$\mathrm{Sep}^{\mathrm{Th}}$ Mouse Hematopoietic Progenitor Cell Isolation Kit and performed colony-forming unit (CFU) assays using MethoCult ${ }^{\text {tm }}$ GF M3434 medium (both from Stem Cell Technologies, Vancouver, BC, Canada), according to the manufacturer's instructions. 
Enzyme-linked immunosorbent assay (ELISA)

Plasma levels of stromal cell-derived factor-1 (SDF-1), matrix metalloproteinase-2 (MMP2), and matrix metalloprotease-9 (MMP9) in mice were measured using the Magnetic Luminex ${ }^{\circ}$ Screening Assay (R\&D Systems), according to the manufacturer's instructions.

\section{Immunohistochemistry of BM sections}

Immunohistochemistry (IHC) was performed on 3- $\mu \mathrm{m}$ formalin-fixed, paraffin-embedded sections from the $\mathrm{BM}$. The following primary antibodies were used: antikeratinocyte-derived cytokine (KC) (Cloud-Clone Corp., Houston, TX, USA; catalog no. PAA041Mu01; 1:50), anti-macrophage inflammatory protein 2 (MIP-2) (Cloud-Clone Corp.; catalog no. PAB603Mu01; 1:100), anti-lipopolysaccharide-inducible CXC chemokine (LIX) (Cloud-Clone Corp.; catalog no. PAA860Mu01; 1:100), anti-MMP2 (Abcam; catalog no. ab37150; 1:200), antiMMP9 (Abcam; catalog no. ab38898; 1:200), and antiSDF-1 (Abcam; catalog no. ab9797; 1:500). In the case of anti-KC, anti-MIP-2, anti-LIX, anti-MMP9, and antiSDF-1, antigen retrieval was performed using a citrate buffer. All slides were scanned using a virtual microscopy scanner (Axio Scan Z1 scanner; Carl Zeiss, Jena, Germany); positive contributions were calculated by summing the highly positive, positive, and low-positive fractions for each staining using the IHC profiler Plugin of ImageJ [20].

\section{Statistical analysis}

Patient demographics and baseline characteristics were compared using Kruskal-Wallis $\mathrm{H}$ and Chi-square tests. Multivariate analysis using the Cox proportional hazards method was performed. Mann-Whitney U, Student's $t$ tests, and analysis of variance were used to analyze differences in data from the in vitro and in vivo experiments, based on the variables involved. A post hoc analysis with Bonferroni correction was performed when statistical differences were identified among the three groups. Data analysis was performed using IBM SPSS Statistics for Windows, version 25.0 (IBM Corp., NY, USA). Significant differences are denoted by $p$-values $<$ 0.05 .

\section{Results}

Etoposide-induced chemo-mobilization is highly effective and exhibits different clinical features, compared to the other mobilization methods

We analyzed data from 173 patients with NHL who underwent PBSCC in the presence of the following chemotherapeutic agents: G-CSF only, $n=33$; cyclophosphamide + G-CSF, $n=24$; and etoposide + G-CSF, $n=$ 116. The baseline characteristics of the patients are summarized in Table 1. The highest yield of CD34+ cells was observed for etoposide + G-CSF (Fig. 1a), a result that remained significant even after adjusting for baseline characteristics (Supplementary Material 3: Table S3). The

Table 1 Baseline characteristics

\begin{tabular}{|c|c|c|c|c|}
\hline Baseline characteristics & $\begin{array}{l}\text { G-CSF only } \\
(n=33)\end{array}$ & $\begin{array}{l}\text { CY+G-CSF } \\
(n=24)\end{array}$ & $\begin{array}{l}\text { ETO+G-CSF } \\
(n=116)\end{array}$ & $p$-value \\
\hline Median age (in years) (range) & $43.0(17.0-67.0)$ & $46.5(20.0-62.0)$ & $52(21.0-65.0)$ & 0.003 \\
\hline Male:female ratio & 2.00 & 2.43 & 1.23 & 0.243 \\
\hline Histology, $n$ (\%) & & & & 0.139 \\
\hline Hodgkin lymphoma & $3(9.1)$ & $4(16.7)$ & $5(4.3)$ & \\
\hline \multicolumn{5}{|l|}{ Non-Hodgkin lymphoma } \\
\hline B cell & $15(45.5)$ & $14(58.3)$ & $65(56.0)$ & \\
\hline T cell & $15(45.5)$ & $6(25.0)$ & $46(39.7)$ & \\
\hline Disease stage, $n$ (\%) & & & & 0.342 \\
\hline Limited stage (Stage I-II) & $8(24.2)$ & $3(12.5)$ & $31(26.7)$ & \\
\hline Advanced stage (Stage III-IV) & $25(75.8)$ & $21(87.5)$ & $85(73.3)$ & \\
\hline Bone marrow involvement at dagnosis, $n(\%)$ & $5(15.2)$ & $6(25.0)$ & $30(27.5)$ & 0.472 \\
\hline Number of previous chemotherapy treatments (range) & $2(1-3)$ & $2(1-3)$ & $1(1-5)$ & 0.139 \\
\hline Disease status before mobilization, $n(\%)$ & & & & 0.080 \\
\hline Complete remission & $12(36.4)$ & $10(41.7)$ & $52(44.8)$ & \\
\hline Partial remission & 19 (57.6) & $12(50.0)$ & $47(40.5)$ & \\
\hline Dose, total ( $\left.\mathrm{mg} / \mathrm{m}^{2}\right)$ (range) & - & $3,000(1,000-3,000)$ & $750(375-750)$ & - \\
\hline Time from diagnosis to start of mobilization (months) (range) & $7.6(3.7-63.3)$ & $16.6(0.7-59.9)$ & $6.2(1.5-148.0)$ & 0.003 \\
\hline Median follow-up duration after mobilization (months) (range) & $12.2(0.1-96.0)$ & $37.8(0.1-92.6)$ & $13.0(1.4-76.8)$ & - \\
\hline Transplantation done, $\boldsymbol{n}(\%)$ & 29 (90.6) & $16(72.7)$ & 112 (96.6) & - \\
\hline
\end{tabular}




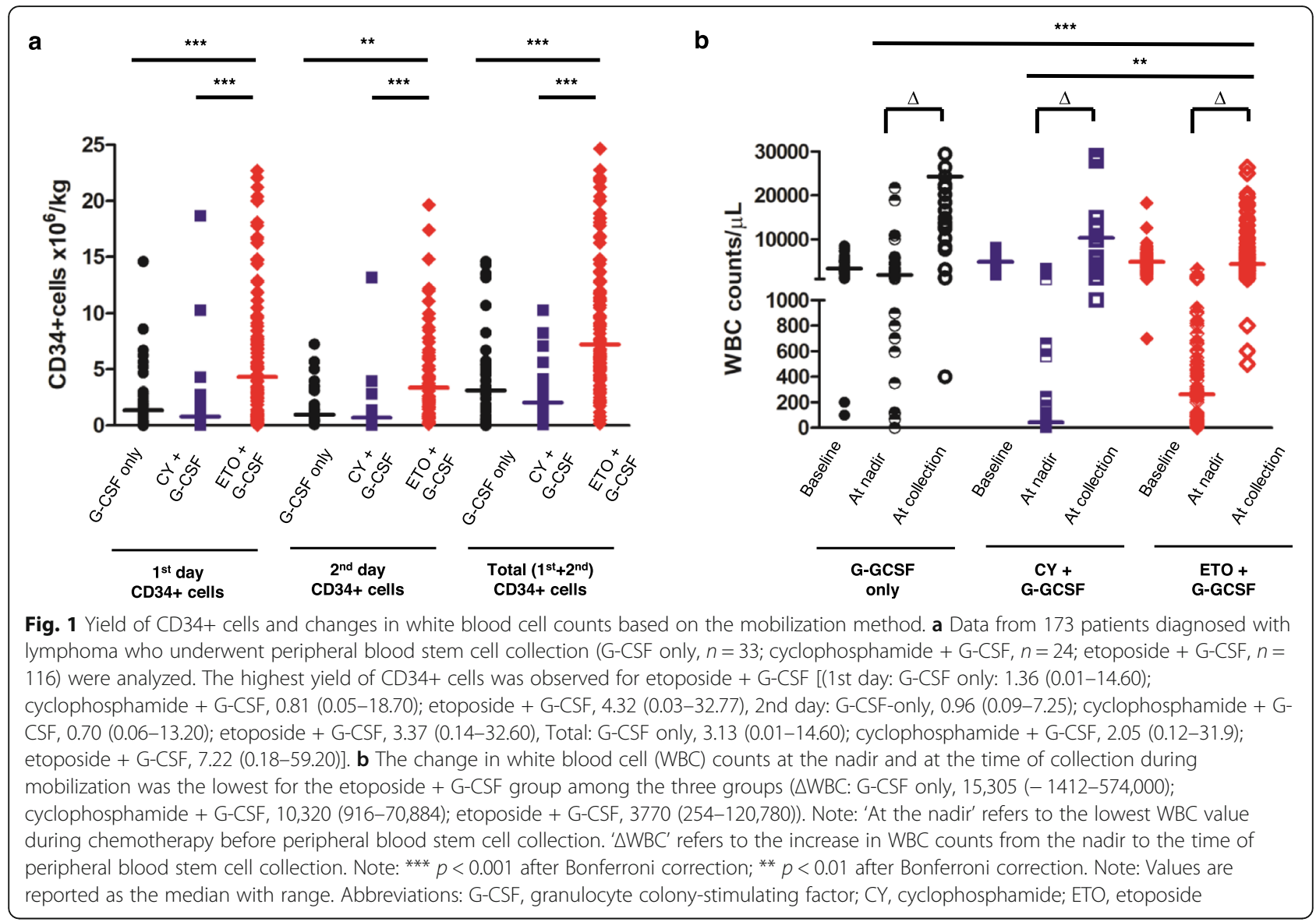

increase in white blood cell (WBC) count (from the nadir to the time of PBSCC) was modest for etoposide + G-CSF, compared with that for G-CSF only and cyclophosphamide + G-CSF (Fig. 1b). In etoposide + G-CSF, WBC counts at the nadir (cyclophosphamide + G-CSF, 41 (93258); etoposide + G-CSF, 262 (1-3160)) were higher, and those at the time of PBSCC (cyclophosphamide + G-CSF, 10,350 (1000-70,900); etoposide + G-CSF, 4380 (500-122, $150)$ ) were lower than the WBC counts in cyclophosphamide + G-CSF ( $p=0.056$ and 0.005 , respectively). Previous studies have reported a positive correlation between the degree of WBC count increase during mobilization and the increase in CD34+ cell yield [21-23]. In the present study, etoposide-induced chemo-mobilization led to the highest CD34+ cell yield, despite the fact that the differences in WBC counts between the nadir and the time of PBSCC were the lowest. Therefore, we suspected that the mechanism underlying HSC mobilization by etoposide might differ from that of G-CSF only and cyclophosphamide. However, our hypothesis must be confirmed because there was heterogeneity among patients in each group and because of the presence of other confounding factors.

\section{Etoposide increases IL-8 secretion from BMSCs and causes long-term MBSC toxicity}

hBMSCs, which constitute the major cell component of the BM niche [24], were isolated from BM (Fig. 2a-b) and treated with various concentrations of cyclophosphamide $(0-12.5 \mathrm{mg} / \mathrm{mL})$ or etoposide $(0-2.0 \mathrm{mg} / \mathrm{mL})$ for $24 \mathrm{~h}$. Drug concentrations sufficient to cause the death of 10,25 , and $50 \%$ of the viable hBMSCs were defined as cytotoxic concentration (CC) 10, CC 25, and CC 50, respectively (Fig. 2c). Data regarding the blood concentrations of the two drugs from patients receiving high-dose cyclophosphamide or etoposide treatment was compiled from the literature. For high-dose cyclophosphamide treatment $\left(1850-7000 \mathrm{mg} / \mathrm{m}^{2}\right)$, the maximum reported serum concentration $\left(\mathrm{C}_{\max }\right)$ was $2.664 \mathrm{mg} / \mathrm{mL}$ $[25,26]$. For high-dose etoposide treatment (1480-1665 $\mathrm{mg} / \mathrm{m}^{2}$ ), the reported $C_{\max }$ was $0.1 \mathrm{mg} / \mathrm{mL}[27,28]$. Based on this information, the CC10 was selected as the drug concentration for further experiments.

hBMSCs were cultured in a medium containing normal saline (control group, $n=4$ ), cyclophosphamide (dose of CC10, $n=5$ ), or etoposide (dose of CC10, $n=5$ ) for $24 \mathrm{~h}$; subsequently, human cytokine analysis was 
a

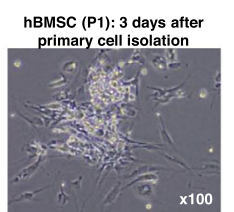

hBMSC (P1): 6 days after

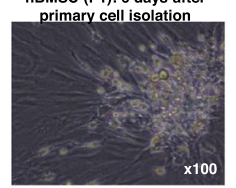

hBMSC (P2): 3 days after

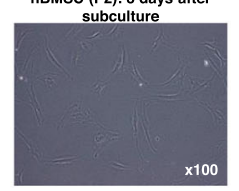

d

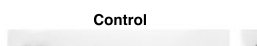

$:: \quad:$

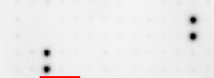

SCF ${ }^{\square}{ }_{\text {SDF-1 }}:$

$:: \quad \square^{\text {сяо }}::$

แ-8 $\square$

:: $:$ :

f
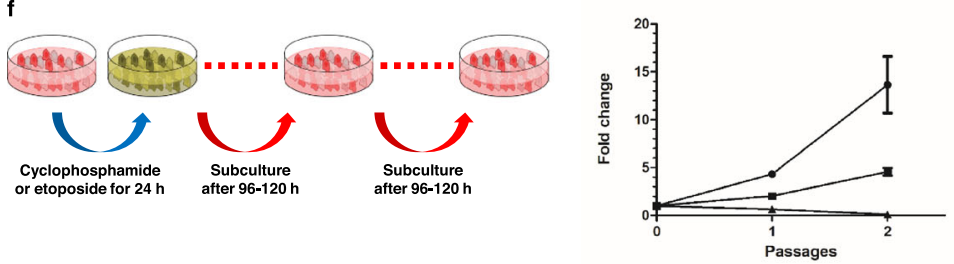

g

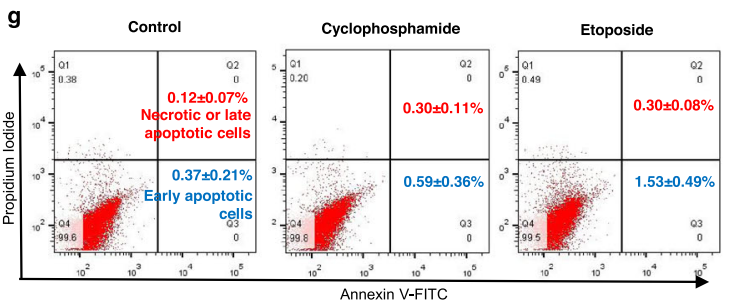

h
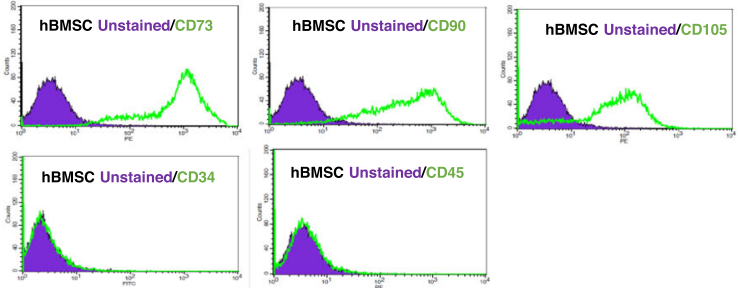

c
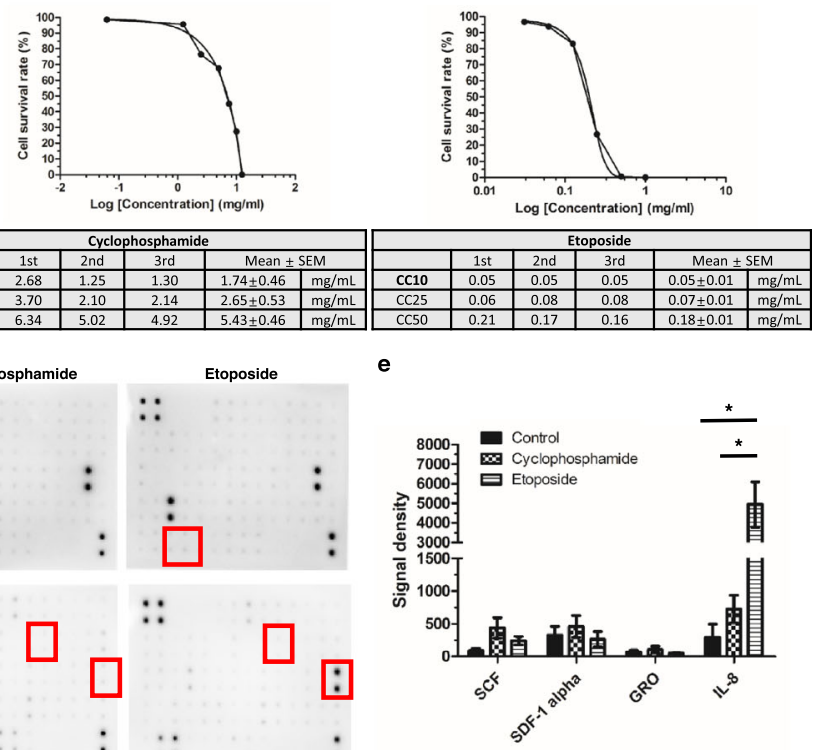

- Control

- Cyclophosphamide

- Etoposide

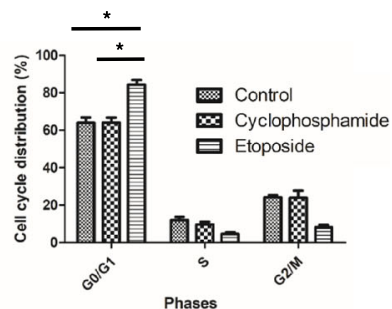

Fig. 2 (See legend on next page.) 


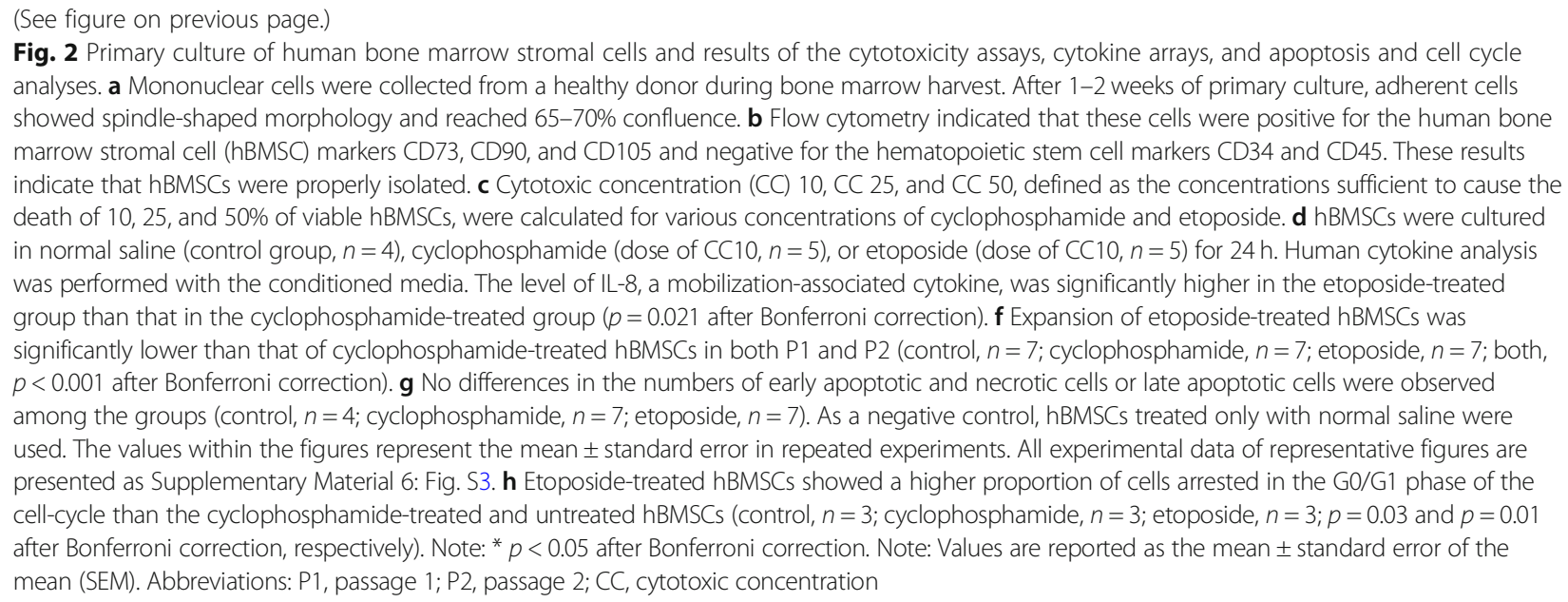

performed using the conditioned media. The level of IL8 , a mobilization-associated cytokine $[29,30]$, was significantly higher in the etoposide-treated group than in the cyclophosphamide-treated group $(p=0.021$ after Bonferroni correction) (Fig. 2d-e). Other mobilizationassociated cytokines showed no significant differences among the groups.

The degree of expansion of etoposide-treated hBMSCs was significantly lower than that of cyclophosphamidetreated hBMSCs for all passages $(p<0.001$ after Bonferroni correction for both) (Fig. 2f). No significant differences in apoptosis were observed among the groups (Fig. 2g). However, cell-cycle analysis revealed a significantly higher proportion of etoposide-treated hBMSCs arrested in the G0/G1 phase than cyclophosphamidetreated and untreated hBMSCs $(p=0.03$ and $p=0.01$ after Bonferroni correction, respectively; Fig. 2h).

\section{IL-8 enhances HSC expansion and is associated with CXCR2, mTOR, and c-MYC activation}

We observed significantly increased IL-8 secretion from hBMSCs treated with etoposide, compared to that from hBMSCs treated with cyclophosphamide. To investigate the manner in which the hBMSC-released IL-8 affects hHSCs in the BM niche, we cultured $2.5 \times 10^{6} \mathrm{hHSCs}$ with $100 \mathrm{ng} / \mathrm{mL}$ IL-8 $(n=12)$ or without IL-8 $(n=12)$ for $24 \mathrm{~h}$ in a conditioned medium collected from 24-h cultures of healthy hBMSCs grown in mesenchymal stem-cell growth medium. Previous experiments had determined the distribution of human cytokines in this conditioned medium (Fig. 2d, control group) and had identified the relatively low IL-8 expression in this medium (Fig. 2e, control group). The numbers of total, CD34+, and CD34+/CD45- cells determined using a hemocytometer and flow cytometric analysis of CD34+ cells cultured with IL-8 were significantly higher than those of cells cultured without IL-8 $(p=0.014$, 0.020 , and 0.039 , respectively) (Fig. 3a). To identify the mechanism underlying the effect of IL-8 on hHSCs, the expression of CXCR2 (an IL-8 receptor) and $m T O R$ and c$M Y C$ (components of IL-8-related signaling pathways) was measured by qRT-PCR. The relative expression of CXCR2, $m T O R$, and $\mathrm{c}-M Y C$ increased at $1 \mathrm{~h}$ after IL-8 treatment (Fig. 3b). The expression of $C X C R 2$ returned to normal $6 \mathrm{~h}$ after IL- 8 treatment, and the expression of mTOR gradually decreased at 6 and $24 \mathrm{~h}$ after IL-8 treatment. In the case of c- $M Y C$, the increased expression lasted up to $24 \mathrm{~h}$.

\section{Etoposide-induced chemo-mobilization increases IL-8- associated cytokine levels, especially in the BM}

We developed mouse models for PB HSC mobilization based on the actual mobilization protocol used in human patients (G-CSF only, $n=8$; cyclophosphamide + G-CSF, $n=8$; etoposide + G-CSF, $n=8$; Fig. 4a-b). Changes in WBC counts at the nadir and at the time of collection (D7) showed patterns similar to those observed in clinical settings (Figs. 1b and 4c). On D7, HPCs were isolated from the $\mathrm{PB}$, and CFUs (CFU-granulocytes, erythrocytes, monocytes, and megakaryocytes; CFU-granulocytes, macrophages; and burst forming unit-erythroids) were counted (Fig. 4d). The cyclophosphamide-treated (total $200 \mathrm{mg} / \mathrm{kg}$ ) and etoposide-treated (total $80 \mathrm{mg} / \mathrm{kg}$ ) groups showed a higher number of CFUs than the G-CSF only group $(p=$ 0.021 and 0.003 after Bonferroni correction, respectively). No significant differences in the total number of CFUs were observed between the cyclophosphamide-treated (total $200 \mathrm{mg} / \mathrm{kg}$ ) and etoposide-treated (total $80 \mathrm{mg} / \mathrm{kg}$ ) groups (G-CSF only, $n=5$; cyclophosphamide + GCSF, $n=5$; etoposide + G-CSF, $n=5$; Fig. 4e). Thus, this condition might be appropriate to investigate the differences in the mechanisms underlying etoposide-induced and other compound-induced chemo-mobilization.

Plasma cytokine levels in whole blood collected from mice on D7 were analyzed. The levels of KC, MIP-2, and LIX, which are IL-8 homologs in mice [31-33], were 
a

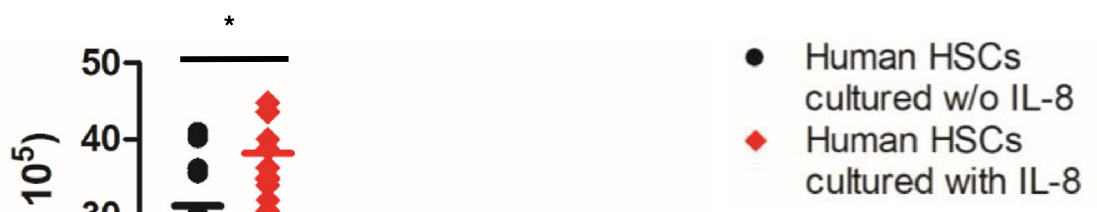

b

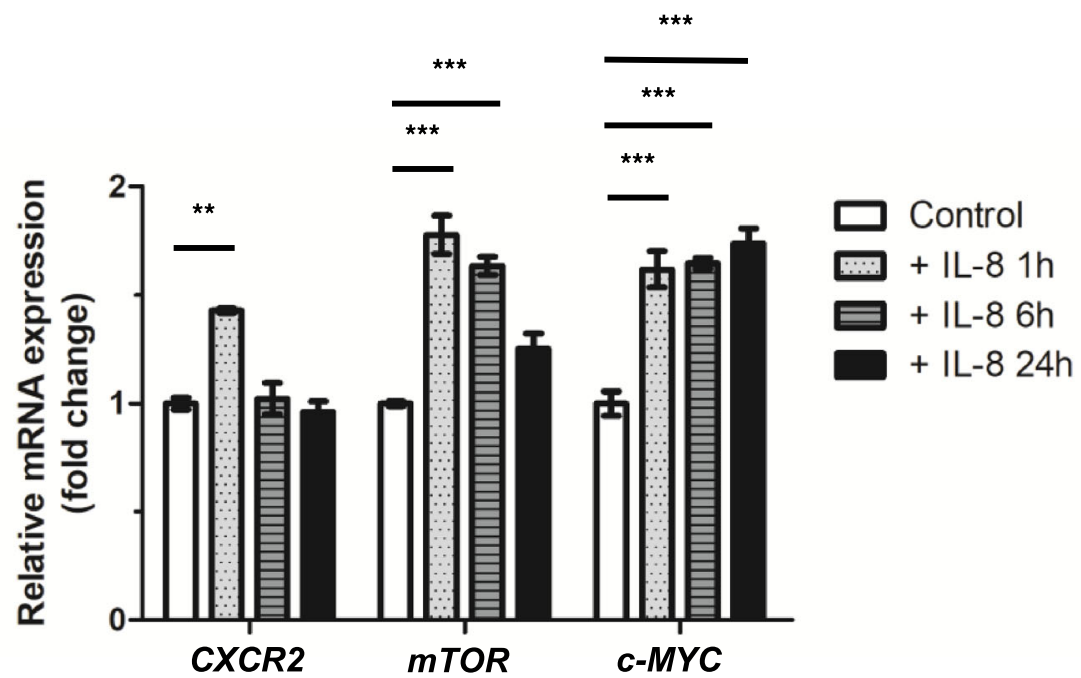

Fig. 3 Effects of increased IL-8 levels on hematopoietic stem cells. a Conditioned media was collected from 24-h cultures of healthy hBMSCS grown in mesenchymal stem cell growth medium. Subsequently, $2.5 \times 10^{6} \mathrm{hHSC}$ were cultured for $24 \mathrm{~h}$ in conditioned media in the presence $n=12)$ and absence $(n=12)$ of IL-8 $(100 \mathrm{ng} / \mathrm{mL})$. The numbers of total, CD34+, and CD34+/CD45- cells were significantly higher in the hHSCs cultured in the presence of IL-8, compared to those in cells cultured without IL-8 ( $p=0.014, p=0.020$, and $p=0.039$, respectively). $\mathbf{b}$ The relative expression of CXCR2, mTOR, and C-MYC increased at $1 \mathrm{~h}$ after IL-8 treatment. The expression of CXCR2 returned to normal after $6 \mathrm{~h}$ of IL-8 treatment, and the expression of mTOR gradually decreased at 6 and $24 \mathrm{~h}$ after IL-8 treatment. In the case of c-MYC, the increased expression lasted up to $24 \mathrm{~h}$. Each experiment was repeated thrice. Note: ${ }^{* *} p<0.001 ;{ }^{* *} p<0.01 ;{ }^{*} p<0.05$. Note: Values are reported as the median with range $(A)$ and the mean \pm SEM (B). Abbreviations: hBMSCs, human bone marrow stromal cells; hHSC, human hematopoietic stem cell

measured (G-CSF only, $n=9$; cyclophosphamide + GCSF, $n=9$; etoposide $+\mathrm{G}$-CSF, $n=9$ ). The level of KC was significantly increased in the etoposide-treated group, compared with that in the cyclophosphamidetreated group ( $p=0.001$ after Bonferroni correction). The levels of the other IL- 8 homologs, MIP-2 and LIX, were also increased in the etoposide-treated group, compared with those in the cyclophosphamide-treated group; however, the differences were not significant. None of the three homologs showed significant differences among the etoposide-treated and G-CSFonly groups (Fig. $5 \mathrm{a}-\mathrm{b}$ ). To confirm that the changes in the plasma levels of KC, MIP-2, and LIX reflected similar changes in the BM, we quantified the IHC images of BM sections using the IHC profiler Plugin of Image) (GCSF only, $n=7$; cyclophosphamide + G-CSF, $n=7$; etoposide + G-CSF, $n=7$ ). The levels of KC, MIP-2, and LIX were all significantly increased in the BM sections from the etoposide-treated group, compared with those from the G-CSF-only and cyclophosphamide-treated 


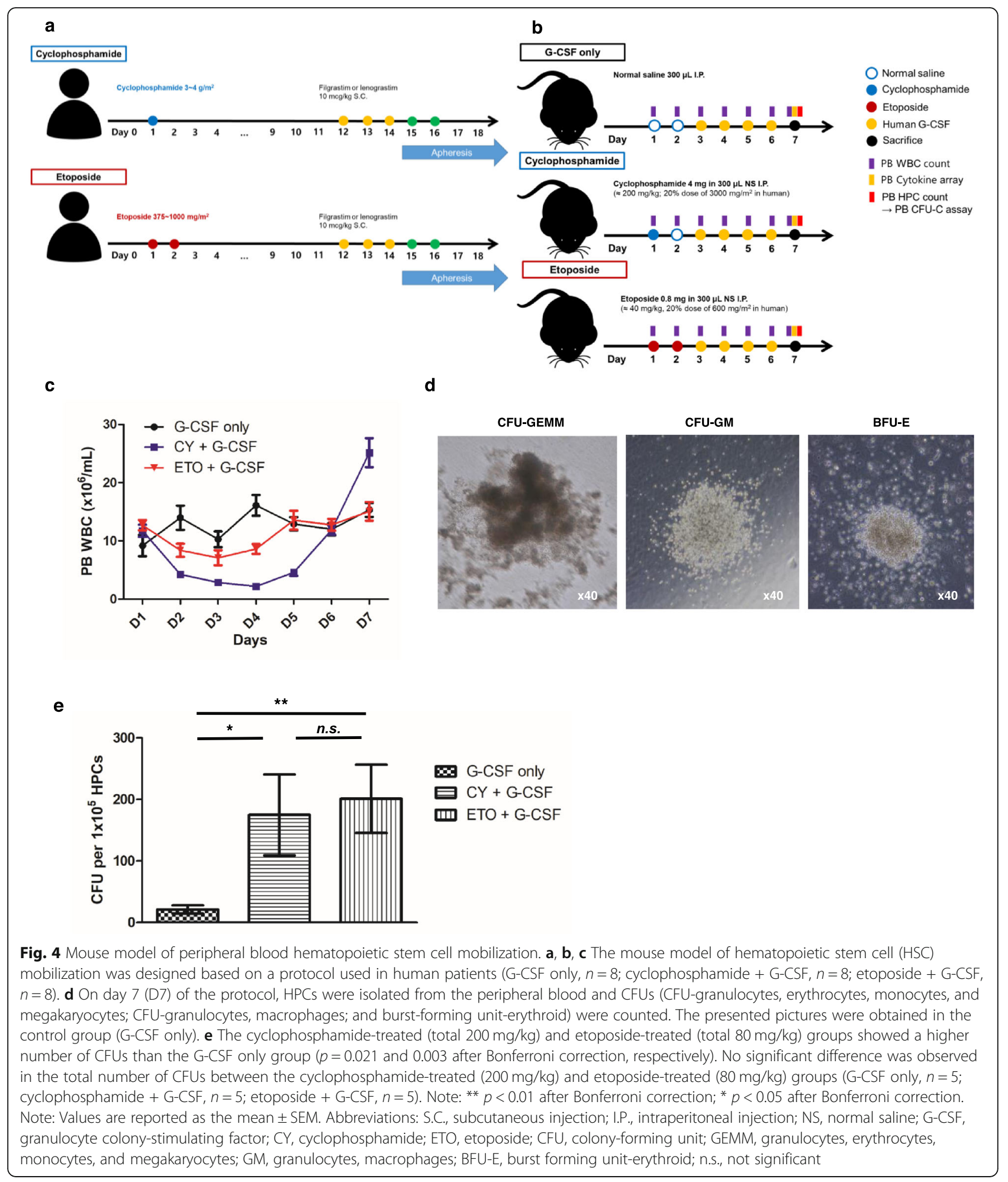




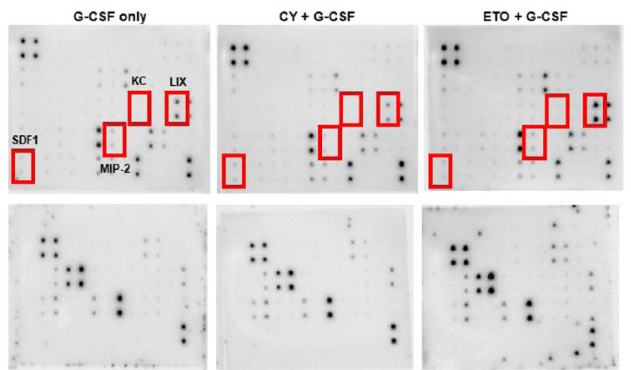

c
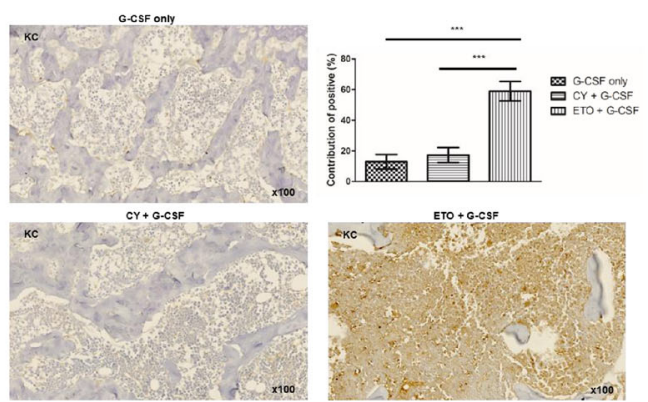

d
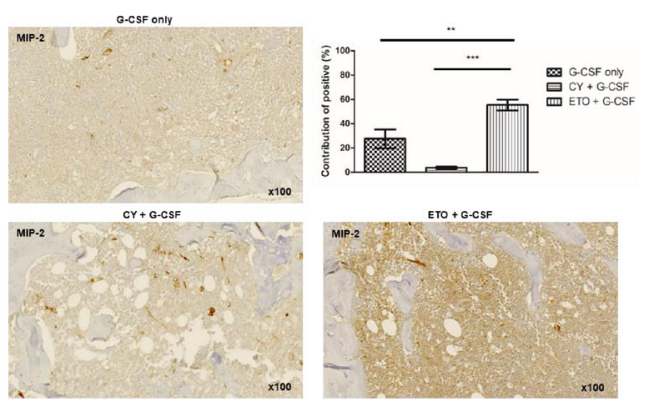

e
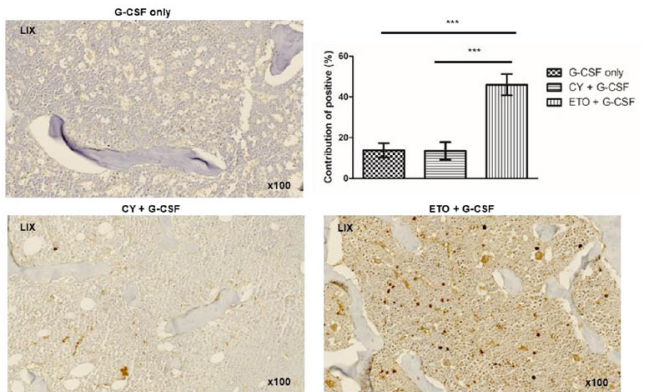

b

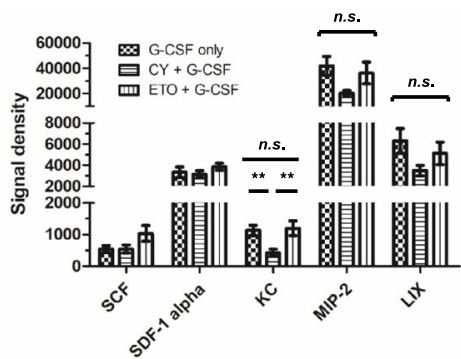

Fig. 5 Keratinocyte-derived cytokine (KC), macrophage inflammatory protein 2 (MIP-2), and lipopolysaccharide-inducible CXC (LIX) expression in the mouse model of peripheral blood hematopoietic stem cell mobilization. $\mathbf{a}, \mathbf{b}$ Plasma cytokine analysis was performed in the mouse model on day 7. Levels of KC, MIP-2, and LIX (IL-8 homologs in mice) were measured (G-CSF only, $n=9$; cyclophosphamide + G-CSF, $n=9$; etoposide + GCSF, $n=9$ ). KC levels significantly increased in the etoposide-treated group, compared with those in the cyclophosphamide-treated group ( $p=$ 0.001 after Bonferroni correction). Levels of the other IL-8 homologs, MIP-2 and LIX, were also increased in the etoposide-treated group but did not show significant differences compared to the cyclophosphamide-treated group. $\mathbf{c}$, d, e To confirm local changes in KC, MIP-2, and LIX in the bone marrow, we quantified IHC images using the IHC profiler plugin of the ImageJ. KC increased significantly in the etoposide-treated group, compared to that in the G-CSF-only and cyclophosphamide-treated groups ( $p<0.001$ and $p<0.001$ after Bonferroni correction, respectively). Levels of the other IL-8 homologs, MIP-2 and LIX, increased significantly in the etoposide-treated group, compared to those in the G-CSF-only group and cyclophosphamide-treated group (MIP-2, $p=0.004$ and $p<0.001$ after Bonferroni correction, respectively; LIX, $p<0.001$ and $p<0.001$ after Bonferroni correction, respectively). Note: ${ }^{* *} p<0.001$ after Bonferroni correction; ${ }^{* *} p<0.01$ after Bonferroni correction. Note: Values are reported as the mean \pm SEM. Abbreviations: G-CSF, granulocyte colony-stimulating factor; CY, cyclophosphamide; ETO, etoposide; n.S., not significant; IHC, immunohistochemistry 
groups $(p<0.001$ and $p<0.001 ; p=0.004$ and $p<0.001$; $p<0.001$ and $p<0.001$ after Bonferroni correction, respectively; Fig. $5 \mathrm{c}-\mathrm{e})$.

\section{Etoposide-induced chemo-mobilization is associated with} increased MMP9 and decreased SDF-1 levels in the BM

The cytokine network was comprehensively analyzed to identify the potential mechanisms underlying etoposideinduced HSC mobilization. Cytokines exhibiting a significant $(p<0.05)$ increase in response to etoposide-induced chemo-mobilization, compared to that in response to G-CSF-only- or cyclophosphamide-induced chemomobilization, in mouse cytokine assays were analyzed by Ingenuity Pathway Analysis (Qiagen, Redwood City, CA, USA; Supplementary Material 4 and 5: Fig. S1 and S2). Network analysis showed that cytokines exhibiting increased levels in response to etoposide-induced chemomobilization were associated with the activation of matrix metalloproteinases (MMPs), which affect the CXCR4/ SDF-1 axis, and are known to be involved in HSC mobilization [34, 35]. Therefore, the expression of MMPs related to HSC mobilization, i.e., MMP2 and MMP9, was assessed. In the PB, the expression of MMP2, MMP9, and SDF-1 did not differ significantly among groups (G-CSFonly, $n=4$; cyclophosphamide chemo-mobilization, $n=4$; etoposide chemo-mobilization, $n=4)$. However, in the BM, MMP9 expression was significantly increased and SDF-1 expression was significantly decreased in the etoposide-induced chemo-mobilization group, compared to that in the other groups (G-CSF-only, $n=7$; cyclophosphamide + G-CSF, $n=7$; etoposide + G-CSF, $n=7$; Fig. 6) .

\section{Discussion}

Our retrospective analysis of clinical data showed that etoposide-induced chemo-mobilization results in the highest yield of CD34+ cells among all three groups analyzed, despite relatively modest changes in PB WBC counts. To our knowledge, this is the first analysis of clinical data pertaining to etoposide-induced chemomobilization. This study suggests the possibility of a different mechanism for chemo-mobilization by etoposide. Our in vitro experiments showed that etoposide significantly increased the secretion of IL-8 by hBMSCs, whereas cyclophosphamide did not. IL-8 is a part of the senescence-associated secretory phenotype; therefore, this finding might be associated with the specific influence of etoposide on hBMSC subcultures, which was not observed upon treatment with cyclophosphamide. This finding might provide a clue to explain the higher efficiency of etoposide at inducing chemo-mobilization compared to that of cyclophosphamide. Studies by Pelus et al. and Fukuda et al. support this hypothesis by showing that the CXCR2 ligand GRO- $\beta$ rapidly mobilizes HSCs and enhances engraftment, although the underlying mechanism has not yet been elucidated [36]. Moreover, we had previously reported that CXCR2 (an IL-8 receptor) stimulation is crucial for maintaining the proliferation of human pluripotent stem cells (hPSCs) $[34,35]$. Therefore, we hypothesized that IL-8 activates the proliferation of hHSCs in a manner similar to that of hPSCs, resulting in more efficient mobilization. To confirm this hypothesis, we performed an in vitro experiment to determine the effect of IL-8 on hHSCs in a simulated BM environment using conditioned medium from healthy hBMSCs; we observed an expansion of CD34+ and CD34+/CD45- cells. We also observed the concomitant significant enhancement in $C X C R 2, m T O R$, and $\mathrm{c}-M Y C$ expression in CD34+ cells following IL-8 stimulation.

Our finding that IL-8 stimulated CXCR2 and mTOR expression is consistent with the results of our studies on hPSCs [37], and with the observation that mTOR activates c-MYC [38]. With respect to the role of c-MYC in hematopoiesis, Wilson et al. reported that $\mathrm{c}-M Y C$ controls the balance between stem cell self-renewal and differentiation, presumably by regulating the interaction between HSCs and their niche [39]. Laurenti et al. demonstrated that the loss of c-MYC alone resulted in the inability of HSCs to differentiate into progenitors; furthermore, the majority of the early and late progenitors stopped proliferating, resulting in HSC accumulation in the BM niche [40]. A study by Ehninger et al. showed that although HSCs express low levels of the c-MYC protein, its expression increases steadily during progenitor differentiation [41]. In a recent study, it was reported that IL-8 activates mTOR and increases endogenous cMYC production, thereby inducing PDL1 expression in gastric cancer [42]. In the present study, IL-8 significantly increased not only the number of CD34+ cells but also that of CD34+/CD45- cells. The results of our previous studies that demonstrated the role of CXCR2 in supporting hPSC proliferation [34, 35], suggest that the activation of CXCR2 by IL-8 may have enhanced hHSC proliferation; however, further studies are necessary to confirm this hypothesis. Therefore, etoposide may induce IL-8 secretion from hBMSCs, which stimulates CXCR2 in HSCs, thereby activating mTOR and c-MYC and leading to HSCs proliferation and progenitor cell differentiation. To our knowledge, this is the first HSC mobilization study to report such a mechanism. Furthermore, this mechanism may also explain the excellent yield at PBSCC during chemo-mobilization induced using etoposide that was also associated with a modest change in WBC count in the PB.

In clinical practice, it is difficult to observe changes in the BM niche in patients undergoing PBSCC. Moreover, cytokine measurements in the PB do not always accurately reflect levels in the BM niche due to systemic confounding 


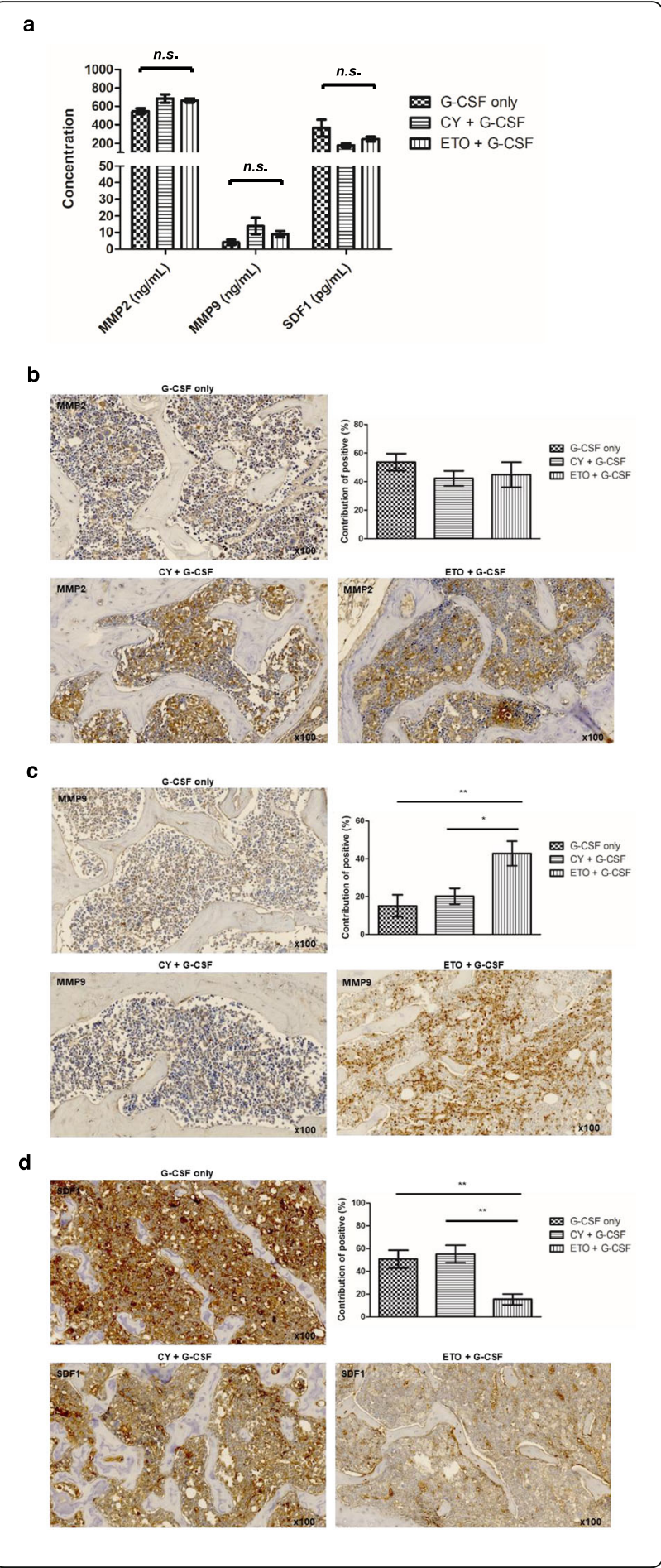

Fig. 6 Matrix metalloprotease (MMP) 2, MMP9, and stromal cellderived factor-1 (SDF-1) expression in the mouse model of peripheral blood hematopoietic stem cell mobilization. a MMP2, MMP9, and SDF1 expression in the peripheral blood did not differ significantly among the groups (G-CSF only, $n=4$; cyclophosphamide + G-CSF, $n=4$; etoposide $+\mathrm{G}-\mathrm{CSF}, n=4)$. $\mathbf{b}, \mathbf{c}, \mathbf{d}$ In the bone marrow, the etoposide + G-CSF group showed a significant increase in MMP9 and decrease in SDF-1 expression, compared to the G-CSF only and cyclophosphamide + G-CSF groups (G-CSF only, $n=7$; cyclophosphamide + G-CSF, $n=7$; etoposide + G-CSF, $n=7$ ). Note: ** $p<0.01$ after Bonferroni correction; ${ }^{*} p<0.05$ after Bonferroni correction. Note: Values are reported as the mean \pm SEM. Abbreviations: G-CSF, granulocyte colony-stimulating factor; CY, cyclophosphamide; ETO, etoposide; n.S., not significant

factors. To overcome these obstacles, we established standardized animal mobilization models that excluded such confounding factors. We were able to simulate the cyclophosphamide and etoposide mobilization patterns observed in clinical practice in two distinct mouse models. Using these models, we confirmed the significantly increased expression of IL-8 homologs and MMP9 and decreased expression of SDF-1 in the BM during etoposide-induced chemo-mobilization, compared to that during G-CSF onlyand cyclophosphamide-induced chemo-mobilization. The levels of IL-8 homologs in the PB during G-CSF-induced mobilization were comparable to those during etoposideinduced chemo-mobilization. Watanabe et al. had previously reported that G-CSF increased the WBC counts and IL-8 levels during mobilization. Increased IL-8 levels were correlated with higher numbers of CD34+ cells in the $\mathrm{PB}$ [43]. G-CSF was associated with polymorphonuclear neutrophils, which leads to increased IL-8 levels, and potentially, mobilization [44-46]. Moschella et al. had reported that cyclophosphamide induced the transcriptional modulation of PB MNCs and IFN-1-related sterile inflammatory responses. In that study, the levels of IL-8, an IFN-1induced proinflammatory mediator in the PB [47], also increased significantly. Thus, inflammatory response could be the reason underlying the increase in IL-8 levels in the PB after etoposide treatment; however, few studies have addressed this issue [48, 49]. Previous studies have reported that IL- 8 is produced by phagocytes and mesenchymal cells exposed to inflammatory stimuli [50], and that etoposide affects the BMSCs $[16,51]$. Therefore, increased IL-8 levels in the PB may be due to inflammatory responses as well as hBMSCs. Additionally, IL-8 may enhance MMP9 production [52], leading to SDF-1 degradation and subsequent mobilization [34, 53, 54]. The results of our animal study revealed that etoposide increases the expression of IL- 8 homologs (KC, MIP-2, and LIX) and MMP9 and decreases SDF-1 expression in the BM, although the levels of these molecules in the PB were similar in all the groups. These findings suggested that the origin of IL-8 in the PB during etoposide-induced chemo-mobilization was predominantly the BM niche rather than systemic inflammation. 
Synthetically, etoposide stimulated hBMSCs to secrete IL-8, which activated CXCR2, mTOR, and c-MYC in the HSCs, resulting in their proliferation. Moreover, MMP9 levels increased and SDF-1 decreased in the BM niche, resulting in HSC mobilization.

The results of this study demonstrate that etoposide causes long-term hBMSC toxicity associated with cellcycle arrest at the G0/G1 phase. Hare et al. had reported that exposure of hBMSCs to sub-lethal doses of etoposide resulted in an increased proportion of cells arrested at the G0/G1 phase [55]. Moreover, BMSCs could not activate non-homologous end-joining repair following etoposide-induced stress after successive passages [55]. Clinical data also suggest that the toxicity of etoposide in the BM niche is higher and lasts longer than that of cyclophosphamide $[9,10]$. However, currently no definitive data are available regarding the adverse effects of etoposide on engraftment or survival. Studies on this topic need to be conducted in future.

Our present study has several limitations, the first of which is the absence of plerixafor + G-CSF, which can induce adequate of the HSCs mobilization with less toxicity. There are two reasons for proceeding without including plerixafor + G-CSF, i.e., (1) plerixafor is often difficult to use clinically in some countries at it is expensive, and (2) the mechanism of action of plerixafor is relatively well-known. For these reasons, we focused on comparing three chemo-mobilization methods (G-CSF only, cyclophosphamide + G-CSF, or etoposide + GCSF) that have been used in clinical practice but whose mechanisms of action are unclear. Second, this study focused predominantly on cytokine or enzyme changes in the BM niche rather than systemic inflammation because previous studies have generally assessed the role of systemic inflammation in mobilization; moreover, we suspected that the effect of etoposide on the BM niche might be the main mechanism underlying HSC mobilization. To this end, we used healthy hBMSCconditioned medium that reflects the environment of the normal BM niche, for culturing the CD34+ hHSCs. A study design investigating both the aspects of mobilization would be very complex. Nevertheless, to our knowledge, this is the first study on the mechanism of etoposide-induced chemo-mobilization that focuses on the BM niche. Additionally, this study describes the establishment of the first mouse model of etoposideinduced chemo-mobilization that reflects the conditions encountered in clinical practice.

\section{Conclusion}

In conclusion, etoposide-induced chemo-mobilization is highly effective for harvesting HSCs from the PB. The mechanism of action of etoposide is associated with increased IL- 8 secretion by hBMSCs, which induces the expansion of HSCs in a manner dependent on CXCR2, mTOR, and c-MYC activation as well as increase and decrease of MMP9 and SDF-1 levels, respectively in the $\mathrm{BM}$ niche. Finally, our results suggest that etoposide exposure should be minimized before and after PBSCT because of its long-term toxicity to hBMSCs. These findings emphasize the need for further studies to develop more efficient and safe chemo-mobilization strategies.

\section{Supplementary information}

Supplementary information accompanies this paper at https://doi.org/10. 1186/s12885-020-07102-x.

\section{Additional file 1.}

Additional file 2.

Additional file 3.

Additional file 4.

Additional file 5 .

Additional file 6 .

\section{Abbreviations}

Auto-PBSCT: Autologous peripheral blood stem cell transplantation: BM: Bone marrow; CFU: Colony-forming unit; Cmax: Maximum reported serum concentration; G-CSF: Granulocyte colony-stimulating factor; hBMSCs: Human bone marrow stromal cells; hHSCs: Human hematopoietic stem cells; HPC: Hematopoietic progenitor cells; hPSC: Human pluripotent stem cell; IHC: Immunohistochemical; KC: Keratinocyte-derived cytokine; LIX: Lipopolysaccharide-inducible CXC chemokine; MIP-2: Macrophage inflammatory protein 2; MMP: Matrix metalloproteinase; MMP2: Matrix metalloproteinase-2; MMP9: Matrix metalloprotease-9; MNC: Mononuclear cells; NHL: Non-Hodgkin's lymphoma; PB: Peripheral blood; PBSCC: Peripheral blood stem cell collection; SDF-1: Stromal cell-derived factor-1; WBC: White blood cell

\section{Acknowledgements}

Not applicable.

\section{Authors' contributions}

B.S.K. designed the study. K.W.K., S.J.L., and J.H.K. performed the experiments, B.H.L., S.J.K., Y.P., and B.S.K. critically reviewed the data analysis. K.W.K. analyzed the data. K.W.K. and B.S.K. wrote the manuscript. All authors approved the final version of the manuscript.

\section{Funding}

This research was supported by a grant from the Korea Health Technology R\&D Project from the Korea Health Industry Development Institute (KHIDI), funded by the Ministry of Health \& Welfare, South Korea (Grant number: HI17C2072). The funding bodies had no role in the design of the study, data collection, analysis, interpretation of data or writing the manuscript.

\section{Availability of data and materials}

All data generated or analyzed during this study are included in this published article and its supplementary information files.

\section{Ethics approval and consent to participate}

A retrospective chart review of patients was approved by an internal board of the Korea University Anam Hospital (IRB No. 2019AN0386) and the Samsung Medical Center (IRB No. 2019-09-085-001), and the requirement for informed consent was waived by each institutional review board. All the procedures for primary hBMSC culture were approved by the internal review board of the Korea University Anam Hospital (IRB No. 2015AN0267), and informed consent was obtained from all individual participants. All experimental procedures using animals complied with the guidelines of the Laboratory Animal Research Center of the Korea University College of Medicine (IRB No. KOREA-2017-0176). 


\section{Consent for publication}

Not applicable.

\section{Competing interests}

The authors declare that they have no competing interests.

\section{Author details}

'Division of Hematology-Oncology, Department of Internal Medicine, Korea University School of Medicine, 73, Goryeodae-ro, Seongbuk-gu, Seoul 02841, South Korea. ${ }^{2}$ Institute of Stem Cell Research, Korea University, Seoul, South Korea. ${ }^{3}$ Department of Biomedical and Science, Graduate School of Medicine, Korea University, Seoul, South Korea. ${ }^{4}$ Division of Hematology-Oncology, Department of Internal Medicine, Sungkyunkwan University School of Medicine, Seoul, South Korea.

\section{Received: 22 January 2020 Accepted: 23 June 2020} Published online: 02 July 2020

\section{References}

1. Duhrsen U, Villeval JL, Boyd J, Kannourakis G, Morstyn G, Metcalf D. Effects of recombinant human granulocyte colony-stimulating factor on hematopoietic progenitor cells in cancer patients. Blood. 1988;72:2074-81.

2. Pavone V, Gaudio F, Guarini A, Perrone T, Zonno A, Curci P, et al. Mobilization of peripheral blood stem cells with high-dose cyclophosphamide or the DHAP regimen plus G-CSF in non-Hodgkin's lymphoma. Bone Marrow Transplant. 2002;29:285-90.

3. Haverkos BM, Huang Y, Elder P, O'Donnell L, Scholl D, Whittaker B, et al. A single center's experience using four different front line mobilization strategies in lymphoma patients planned to undergo autologous hematopoietic cell transplantation. Bone Marrow Transplant. 2017;52:561-6.

4. Cottler-Fox MH, Lapidot T, Petit I, Kollet O, DiPersio JF, Link D, et al. Stem cell mobilization. Hematol Am Soc Hematol Educ Program. 2003;2003:419-37.

5. Levesque JP, Hendy J, Takamatsu Y, Simmons PJ, Bendall LJ. Disruption of the CXCR4/CXCL12 chemotactic interaction during hematopoietic stem cell mobilization induced by GCSF or cyclophosphamide. J Clin Invest. 2003;111: 187-96.

6. de Mel S, Chen Y, Lin A, Soh TG, Ooi M, Yap ES, et al. Vinorelbinecyclophosphamide compared to cyclophosphamide in peripheral blood stem cell mobilization for multiple myeloma. Hematol Oncol Stem Cell Ther. 2018;11:225-32.

7. Jantunen E, Putkonen M, Nousiainen T, Pelliniemi T, Mahlamaki E, Remes K. Low-dose or intermediate-dose cyclophosphamide plus granulocyte colony-stimulating factor for progenitor cell mobilisation in patients with multiple myeloma. Bone Marrow Transplant. 2003;31:347-51.

8. Reiser M, Josting A, Draube A, Mapara MY, Scheid C, Chemnitz J, et al. Successful peripheral blood stem cell mobilization with etoposide (VP-16) in patients with relapsed or resistant lymphoma who failed cyclophosphamide mobilization. Bone Marrow Transplant. 1999;23:1223-8.

9. Milone G, Leotta S, Battiato K, Murgano P, Mercurio S, Strano A, et al. Intermediate dose etoposide plus G-CSF $16 \mathrm{~g} / \mathrm{kg}$ is more effective than cyclophosphamide $4 \mathrm{~g} / \mathrm{m}$ (2) plus G-CSF $10 \mathrm{~g} / \mathrm{kg}$ in PBSC mobilization of lymphoma patients. Leuk Lymphoma. 2007;48:1950-60.

10. Hyun SY, Cheong JW, Kim SJ, Min YH, Yang DH, Ahn JS, et al. High-dose etoposide plus granulocyte colony-stimulating factor as an effective chemomobilization regimen for autologous stem cell transplantation in patients with non-Hodgkin lymphoma previously treated with CHOP-based chemotherapy: a study from the consortium for improving survival of lymphoma. Biol Blood Marrow Transplant. 2014;20:73-9.

11. Wood WA, Whitley J, Goyal R, Brown PM, Sharf A, Irons R, et al. Effectiveness of etoposide chemomobilization in lymphoma patients undergoing autoSCT. Bone Marrow Transplant. 2013;48:771-6.

12. Wood WA, Whitley J, Moore D, Sharf A, Irons R, Rao K, et al. Chemomobilization with etoposide is highly effective in patients with multiple myeloma and overcomes the effects of age and prior therapy. Biol Blood Marrow Transplant. 2011;17:141-6.

13. Park Y, Kim DS, Jeon MJ, Lee BH, Yu ES, Kang KW, et al. Single-dose etoposide is an effective and safe protocol for stem cell mobilization in patients with multiple myeloma. J Clin Apher. 2019. https://doi.org/10.1002/ jca.21734.
14. Kollmannsberger C, Beyer J, Droz JP, Harstrick A, Hartmann JT, Biron P, et al. Secondary leukemia following high cumulative doses of etoposide in patients treated for advanced germ cell tumors. J Clin Oncol. 1998;16:3386-91.

15. Relling MV, Boyett JM, Blanco JG, Raimondi S, Behm FG, Sandlund JT, et al. Granulocyte colony-stimulating factor and the risk of secondary myeloid malignancy after etoposide treatment. Blood. 2003;101:3862-7.

16. Gibson LF, Fortney J, Landreth KS, Piktel D, Ericson SG, Lynch JP. Disruption of bone marrow stromal cell function by etoposide. Biol Blood Marrow Transplant. 1997;3:122-32.

17. Tay J, Levesque JP, Winkler IG. Cellular players of hematopoietic stem cell mobilization in the bone marrow niche. Int J Hematol. 2017;105:129-40.

18. Livak KJ, Schmittgen TD. Analysis of relative gene expression data using realtime quantitative PCR and the 2- $\Delta \Delta C T$ method. Methods. 2001;25:402-8.

19. Morrison SJ, Wright DE, Weissman IL. Cyclophosphamide/granulocyte colony-stimulating factor induces hematopoietic stem cells to proliferate prior to mobilization. Proc Natl Acad Sci U S A. 1997;94:1908-13.

20. Varghese F, Bukhari AB, Malhotra R, De A. IHC profiler: an open source plugin for the quantitative evaluation and automated scoring of immunohistochemistry images of human tissue samples. PLoS One. 2014;9:e96801.

21. Grigg AP, Roberts AW, Raunow H, Houghton S, Layton JE, Boyd AW, et al. Optimizing dose and scheduling of filgrastim (granulocyte colonystimulating factor) for mobilization and collection of peripheral blood progenitor cells in normal volunteers. Blood. 1995;86:4437-45.

22. Lack NA, Green B, Dale DC, Calandra GB, Lee H, MacFarland RT, et al. A pharmacokinetic-pharmacodynamic model for the mobilization of CD34+ hematopoietic progenitor cells by AMD3100. Clin Pharmacol Ther. 2005;77: 427-36.

23. Abraham M, Biyder K, Begin M, Wald H, Weiss ID, Galun E, et al. Enhanced unique pattern of hematopoietic cell mobilization induced by the CXCR4 antagonist 4F-benzoyl-TN14003. Stem Cells. 2007;25:2158-66.

24. Morrison SJ, Scadden DT. The bone marrow niche for haematopoietic stem cells. Nature. 2014;505:327-34.

25. Balasubramanian P, Desire S, Panetta JC, Lakshmi KM, Mathews V, George B, et al. Population pharmacokinetics of cyclophosphamide in patients with thalassemia major undergoing HSCT. Bone Marrow Transplant. 2012;47:1178-85.

26. Hassan M, Ljungman P, Ringden O, Hassan Z, Oberg G, Nilsson C, et al. The effect of busulphan on the pharmacokinetics of cyclophosphamide and its 4-hydroxy metabolite: time interval influence on therapeutic efficacy and therapy-related toxicity. Bone Marrow Transplant. 2000;25:915-24.

27. Wurthwein G, Klingebiel T, Krumpelmann S, Metz M, Schwenker K, Kranz K, et al. Population pharmacokinetics of high-dose etoposide in children receiving different conditioning regimens. Anti-Cancer Drugs. 2002;13:101-10.

28. Mross K, Bewermeier P, Kruger W, Stockschlader M, Zander A, Hossfeld DK. Pharmacokinetics of undiluted or diluted high-dose etoposide with or without busulfan administered to patients with hematologic malignancies. J Clin Oncol. 1994;12:1468-74.

29. Laterveer L, Lindley IJ, Hamilton MS, Willemze R, Fibbe WE. Interleukin-8 induces rapid mobilization of hematopoietic stem cells with radioprotective capacity and long-term myelolymphoid repopulating ability. Blood. 1995;85: 2269-75.

30. Fibbe WE, Pruijt JF, Velders GA, Opdenakker G, van Kooyk Y, Figdor CG, et al. Biology of IL-8-induced stem cell mobilization. Ann N Y Acad Sci. 1999;872: 71-82.

31. Hol J, Wilhelmsen L, Haraldsen G. The murine IL-8 homologues KC, MIP-2, and LIX are found in endothelial cytoplasmic granules but not in WeibelPalade bodies. J Leukoc Biol. 2010;87:501-8.

32. Singer M, Sansonetti PJ. IL-8 is a key chemokine regulating neutrophil recruitment in a new mouse model of Shigella- induced colitis. J Immunol. 2004;173:4197-206.

33. Hang L, Frendeus B, Godaly G, Svanborg C. Interleukin-8 receptor knockout mice have subepithelial neutrophil entrapment and renal scarring following acute pyelonephritis. J Infect Dis. 2000;182:1738-48.

34. Fibbe WE, Pruijt JF, van Kooyk Y, Figdor CG, Opdenakker G, Willemze R. The role of metalloproteinases and adhesion molecules in interleukin-8-induced stem-cell mobilization. Semin Hematol. 2000;37:19-24.

35. Shirvaikar N, Marquez-Curtis LA, Janowska-Wieczorek A. Hematopoietic stem cell mobilization and homing after transplantation: the role of MMP-2, MMP-9, and MT1-MMP. J Biochem Res Intnl. 2012;2012:11.

36. Pelus LM, Fukuda S. Peripheral blood stem cell mobilization: the CXCR2 ligand GRObeta rapidly mobilizes hematopoietic stem cells with enhanced engraftment properties. Exp Hematol. 2006;34(8):1010-20. 
37. Jung JH, Kang KW, Kim J, Hong SC, Park Y, Kim BS. CXCR2 inhibition in human pluripotent stem cells induces predominant differentiation to mesoderm and endoderm through repression of MTOR, beta-catenin, and hTERT activities. Stem Cells Dev. 2016;25:1006-19.

38. Luo G, Li B, Duan C, Cheng Y, Xiao B, Yao F, et al. CMyc promotes cholangiocarcinoma cells to overcome contact inhibition via the mTOR pathway. Oncol Rep. 2017;38:2498-506.

39. Wilson A, Murphy MJ, Oskarsson T, Kaloulis K, Bettess MD, Oser GM, et al. CMyc controls the balance between hematopoietic stem cell self-renewal and differentiation. Genes Dev. 2004;18:2747-63.

40. Laurenti E, Varnum-Finney B, Wilson A, Ferrero I, Blanco-Bose WE, Ehninger A, et al. Hematopoietic stem cell function and survival depend on c-Myc and N-Myc activity. Cell Stem Cell. 2008:3:611-24.

41. Ehninger A, Boch T, Uckelmann H, Essers MA, Mudder K, Sleckman BP, et al. Posttranscriptional regulation of c-Myc expression in adult murine HSCs during homeostasis and interferon-alpha-induced stress response. Blood. 2014;123:3909-13.

42. Sun L, Wang Q, Chen B, Zhao Y, Shen B, Wang H, et al. Gastric cancer mesenchymal stem cells derived IL-8 induces PD-L1 expression in gastric cancer cells via STAT3/mTOR-c-Myc signal axis. Cell Death Dis. 2018;9:928.

43. Watanabe T, Kawano Y, Kanamaru S, Onishi T, Kaneko S, Wakata Y, et al. Endogenous interleukin-8 (IL-8) surge in granulocyte colony-stimulating factor-induced peripheral blood stem cell mobilization. Blood. 1999;93: 1157-63.

44. Cassatella MA, Bazzoni F, Ceska M, Ferro I, Baggiolini M, Berton G. IL-8 production by human polymorphonuclear leukocytes. The chemoattractant formyl-methionyl-leucyl-phenylalanine induces the gene expression and release of IL-8 through a pertussis toxin-sensitive pathway. J Immunol. 1992; 148:3216-20.

45. Cassatella MA. The production of cytokines by polymorphonuclear neutrophils. Immunol Today. 1995;16:21-6.

46. Pruijt JF, Verzaal P, van Os R, de Kruijf EJ, van Schie ML, Mantovani A, et al. Neutrophils are indispensable for hematopoietic stem cell mobilization induced by interleukin-8 in mice. Proc Natl Acad Sci U S A. 2002;99:6228-33.

47. Moschella F, Torelli GF, Valentini M, Urbani F, Buccione C, Petrucci MT, et al. Cyclophosphamide induces a type I interferon-associated sterile inflammatory response signature in cancer patients' blood cells: implications for cancer chemoimmunotherapy. Clin Cancer Res. 2013;19:4249-61.

48. Kawagishi C, Kurosaka K, Watanabe N, Kobayashi Y. Cytokine production by macrophages in association with phagocytosis of etoposide-treated P388 cells in vitro and in vivo. Biochim Biophys Acta. 2001;1541:221-30.

49. Tokarz P, Błasiak J. Role of DNA methylation in colorectal cancer. Postepy Biochem. 2013;59:267-79.

50. Baggiolini M, Clark-Lewis I. Interleukin-8, a chemotactic and inflammatory cytokine. FEBS Lett. 1992;307:97-101.

51. Li J, Law HK, Lau YL, Chan GC. Differential damage and recovery of human mesenchymal stem cells after exposure to chemotherapeutic agents. Br J Haematol. 2004;127:326-34.

52. Li A, Dubey S, Varney ML, Dave BJ, Singh RK. IL-8 directly enhanced endothelial cell survival, proliferation, and matrix metalloproteinases production and regulated angiogenesis. J Immunol. 2003;170:3369-76.

53. Pruijt JF, Fibbe WE, Laterveer $L$, et al. Prevention of interleukin-8-induced mobilization of hematopoietic progenitor cells in rhesus monkeys by inhibitory antibodies against the metalloproteinase gelatinase B (MMP-9). Proc Natl Acad Sci USA. 1999;96(19):10863-8. https://doi.org/10.1073/pnas. 96.19.10863.

54. Jin F, Zhai Q, Qiu L, Meng H, Zou D, Wang Y, et al. Degradation of BM SDF1 by MMP-9: the role in G-CSF-induced hematopoietic stem/progenitor cell mobilization. Bone Marrow Transplant. 2008;42:581.

55. Hare I, Gencheva M, Evans R, Fortney J, Piktel D, Vos JA, et al. In vitro expansion of bone marrow derived mesenchymal stem cells alters DNA double strand break repair of etoposide induced DNA damage. Stem Cells Intl. 2016;2016:8270464.

\section{Publisher's Note}

Springer Nature remains neutral with regard to jurisdictional claims in published maps and institutional affiliations.

\section{Ready to submit your research? Choose BMC and benefit from:}

- fast, convenient online submission

- thorough peer review by experienced researchers in your field

- rapid publication on acceptance

- support for research data, including large and complex data types

- gold Open Access which fosters wider collaboration and increased citations

- maximum visibility for your research: over $100 \mathrm{M}$ website views per year

At BMC, research is always in progress.

Learn more biomedcentral.com/submissions 